\title{
Article
}

\section{Thermodynamic Evaluation of Sea Water to Degraded Nuclear Fuel in Severe Accident of LWR}

\author{
Masaki KURATA $^{1, *}$, Noriko SHIRASU ${ }^{1}$ and Toru OGAWA ${ }^{2}$ \\ ${ }^{1}$ Japan Atomic Energy Agency, Nuclear Science and Engineering Directorate, 2-4 Shirane, Shirakata, Tokai-mura, Naka-gun, \\ Ibaraki 319-1195, Japan \\ ${ }^{2}$ Nagaoka University of Technology, 1603-1 Kamitomioka-cho, Nagaoka-shi, Niigata 940-2188, Japan
}

\begin{abstract}
In the Fukushima Daiichi Nuclear Power Plant Accident, a large amount of seawater was introduced into reactor pressure vessels. Sodium and chloride ions, as well as several minor elements contained in seawater, such as $\mathrm{K}, \mathrm{Ca}, \mathrm{Mg}$, and $\mathrm{S}$, possibly reacted with degraded fuel debris or molten corium. Considering possible chemical reactions, various concerns such as volatilization of fission products, characterization of fuel debris, and formation of corrosive gases are discussed. Thermodynamic evaluation can give useful information on the general tendency of these seawater effects. The volatility of Cs, Sr, and Te potentially increases because of the change in stable chemical species. Corrosive gases, such as $\mathrm{HCl}$ and $\mathrm{H}_{2} \mathrm{~S}$, may be generated by the heating of seawater to high temperatures. These phenomena are predicted to vary according to the oxygen potential.
\end{abstract}

KEYWORDS: thermodynamic evaluation, severe nuclear accident, fission product, volatilization, source term, seawater, fuel degradation, corium, fuel debris

\section{Introduction}

In the severe accident at the Fukushima Daiichi Nuclear Power Plant (FDNPP), seawater was used as the water injection source after the loss of cooling ability. Furthermore, the Nuclear and Industrial Safety Agency (NISA) selected seawater as the final water source when a severe accident occurs. However, the influence of seawater injected into the damaged reactor core in a severe accident has rarely been studied. In addition to the main solutes in seawater, sodium and chloride ions, a considerable quantity of other elements are present, including potassium, calcium, magnesium, and sulfur (sulfate group). These elements readily form compounds with various other elements, which are concentrated when the moisture evaporates at high temperatures and may cause various chemical reactions with damaged fuel. Takano et al. investigated high temperature reaction tests on seawater condensates and uranium dioxide. The results indicated that calcium and magnesium are likely to react with fuel debris, although no obvious chemical reaction takes place between sodium chloride and uranium dioxide, which

* Corresponding author, E-mail: kurata.masaki@jaea.go.jp

DOI : 10.15669 /fukushimainsights.Vol.4.219

(C) 2021 Atomic Energy Society of Japan. All rights reserved.

Originally published in Transactions of the Atomic Energy Society of Japan (ISSN 1347-2879), Vol. 12, No. 4, p.286-294

(2013) in Japanese. (Japanese version accepted: July 25, 2013) 
was a point of concern in the beginning ${ }^{1)}$. On the other hand, the evaporation of fission products (FP) changes because of the variation in stability of chemical species due to their interaction with seawater condensates. Furthermore, various gases may be generated from the exposure of seawater to high temperatures, and some of them may be transformed to corrosive gases.

These chemical reactions are expected to drastically change according to the oxygen potential of the system. In a severe accident, it is considered that one of the major factors that control the oxygen potential of degraded fuel is the oxidation reaction of zircalloy ${ }^{2}$. In the early stages of an accident, the oxygen potential in the degraded fuel, excluding the surface that lies in direct contact with cooling water or steam, is presumably maintained at a low value because a large quantity of metallic zirconium remains. As the accident progresses, the oxygen potential is considered to rapidly increase when almost all the zirconium is oxidized. This implies that the influence of seawater on FP evaporation, the chemical status of fuel debris, and the generation of corrosive gases will vary depending on which stage in the severe accident the seawater is supplied. Furthermore, it also implies that the influence of seawater depends on the components of the structural substances in the reactor, which differ according to reactor type (PWR or BWR). For a BWR that contains a large quantity of metallic zirconium in the reactor, a status of low oxygen potential is likely to be maintained for an extended period, compared to a PWR. Furthermore, for a BWR, the high percentage of structural materials, such as stainless steel and inconel alloy, has to be carefully considered in advance.

Because boric acid is contained in the coolant of a PWR, the focus is on $\mathrm{CsBO}_{2}$, as a form of cesium that may be significant in a severe accident ${ }^{3}$. A large amount of $\mathrm{B}_{4} \mathrm{C}$ is used in a BWR as control blade material, and the boric acid or carbon may cause complicated chemical reactions with FP. Regarding this point, Shirasu et al. conducted an analysis using a similar method as in this report ${ }^{4}$.

It requires great effort to deal with these phenomena of concern that are likely occur with exposure to introduced seawater. Acquiring experimental data with repeatability is expected to be difficult because the events in an accident form a complex system with many components. In such a case, a chemical equilibrium computation based on a thermodynamic approach is actively applied as an evaluation method that approximates the chemical events. In this study, the evaluation of various concerns that are presumed to be brought about by the introduction of seawater was attempted.

\section{Analysis Method}

\section{Thermodynamic Database and Equilibrium Computation Tool}

For this study, the European SGTE (Scientific Group Thermodynamics Europe) database SSUB4 was adopted ${ }^{5)}$. As an equilibrium computation tool, chemical equilibrium computation software Thermocalc ver.S by European Thermo-Calc Software ${ }^{6}$ was used.

For proper understanding of the information acquired from the chemical equilibrium computations, the following issues are important. First, a preliminary survey of the contents of the database needs to be conducted in detail. In a severe accident, it is known that organic iodine compounds may be generated ${ }^{7}$. However, because there is almost no existing thermodynamic database, including SSUB4, that integrates the data of organic iodine compounds, the evaluation of the behavior of iodine is incomplete. The database provides only information about the thermal decomposition of cesium iodide (CsI), which has a high probability of formation. Furthermore, where mutual solubility data between compounds is necessary, for instance, in the 
calculation of the chemical state of the matrix phase of fuel debris, existing databases are not suitable for use because they rarely include any data regarding the mutual solubility of nuclear fuel or zircalloy. In this area, evaluations by Gueneau et al ${ }^{8)}$. and by Shirasu et al ${ }^{9}$. are in progress. Second, it is essential to conduct a parallel computation under various assumptions in addition to the simulated computation of actual reactor conditions. The chemical status varies from hour to hour in a severe accident. Based on various assumptions, it is possible to survey the trend of the chemical reactions by performing a so-called "mapping" of thermodynamic states. In this research, a model computation is conducted hypothetically, assuming such conditions as the progress of oxidation not only on zircalloy but also on the steel structural materials, and the reactions between the fuel rods and seawater.

\section{Analysis Conditions}

The quantity of different materials used in the calculation was determined in the following manner. The estimated values for the fuel, cladding, and structural materials for Unit 2 were taken from the FDNPS ${ }^{10}$. Regarding seawater, the values determined by Nozaki were adopt$\mathrm{ed}^{11)}$. The concentrations of the FP were calculated using the ORIGEN-II code ${ }^{12)}$, by referring to the averaged burn-up of Unit 2, summarized in the first step, and then considering the amount of volatile FP, such as cesium (Cs), strontium ( $\mathrm{Sr}$ ), iodine (I), tellurium (Te), molybdenum $(\mathrm{Mo})$, ruthenium $(\mathrm{Ru})$, and niobium $(\mathrm{Nb})$, in the second step. These elements are presumed to interact significantly with seawater. Values were standardized with respect to 1 mole of $\mathrm{UO}_{2}$ and were used as a standard condition in the present study. These are summarized in Table 1 and Table 2. Here, the quantity of actinide elements in the fuel was represented by $\mathrm{UO}_{2}$, the quantity of claddings and channel boxes was represented by $\mathrm{Zr}$, and the quantity of structural materials was represented by Fe. The oxygen potential in the fuel before the severe accident was assumed to be represented by a chemical condition in which some of the Mo is oxidized. Furthermore, the pressure was assumed to be $1 \mathrm{~atm}$. Current thermodynamic data stored in the database do not have proper description regarding influence of pressure. Present evaluation was performed by assuming $1 \mathrm{~atm}$.

\section{Analysis Method}

To evaluate the chemical status of various elements in the degraded fuels, it is necessary to evaluate the oxygen potential of the system in an analysis. In this study, the evaluation was

Table 1 Initial conditions for degraded fuel

\begin{tabular}{cc}
\hline Component & $\begin{array}{c}\text { Mole amount } \\
\text { (normalized with respect to } 1 \mathrm{~mol}-\mathrm{UO}_{2} \text { ) }\end{array}$ \\
\hline Fuel $\left(\mathrm{UO}_{2}\right)$ & $1.00 \mathrm{E}+00$ \\
\hline Zry $(\mathrm{Zr})$ & $1.28 \mathrm{E}+00$ \\
S.S. $(\mathrm{Fe})$ & $8.27 \mathrm{E}-01$ \\
\hline $\mathrm{Sr}$ & $1.82 \mathrm{E}-03$ \\
$\mathrm{Nb}$ & $4.05 \mathrm{E}-05$ \\
$\mathrm{Mo}$ & $5.89 \mathrm{E}-03$ \\
$\mathrm{Ru}$ & $3.67 \mathrm{E}-03$ \\
$\mathrm{Te}$ & $6.13 \mathrm{E}-04$ \\
$\mathrm{I}$ & $2.82 \mathrm{E}-04$ \\
$\mathrm{Cs}$ & $3.63 \mathrm{E}-03$ \\
\hline
\end{tabular}


Table 2 Chemical composition of sea-water

\begin{tabular}{cc}
\hline Component & Concentration $(\mathrm{mg} / \mathrm{L})$ \\
\hline $\mathrm{Na}$ & $1.08 \mathrm{E}+04$ \\
$\mathrm{Mg}$ & $1.28 \mathrm{E}+03$ \\
$\mathrm{~S}$ & $8.98 \mathrm{E}+02$ \\
$\mathrm{~K}$ & $3.99 \mathrm{E}+02$ \\
$\mathrm{Ca}$ & $4.12 \mathrm{E}+02$ \\
$\mathrm{Cl}$ & $1.94 \mathrm{E}+04$ \\
\hline
\end{tabular}

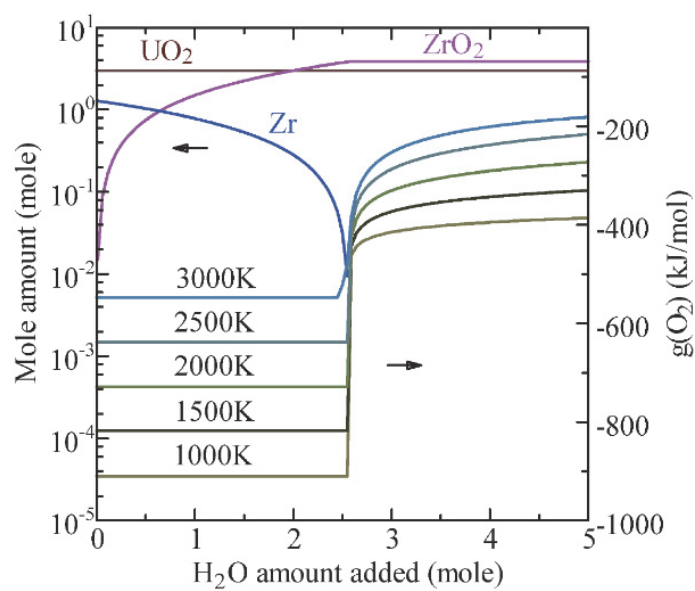

Figure 1 Variation in oxygen potential, $\mathrm{g}\left(\mathrm{O}_{2}\right)$, and progress in $\mathrm{Zr}$ oxidation with respect to added water amount

implemented as follows.

First, the amount of $\mathrm{H}_{2} \mathrm{O}$ added to 1 mole of $\mathrm{UO}_{2}$ and 1.282 mole of $\mathrm{Zr}$ was varied, and the changes in the chemical forms and oxygen potential $\left(\mathrm{g}\left(\mathrm{O}_{2}\right)\right)$ were evaluated.

Figure 1 shows the variation in $\mathrm{g}\left(\mathrm{O}_{2}\right)$ at several temperatures, and the degree of oxidation of $\mathrm{Zr}$ as a function of the amount of added $\mathrm{H}_{2} \mathrm{O}$. The conditions in the leftmost of the figure correspond to no oxidation of $\mathrm{Zr}$ (i.e., the condition before operation of nuclear reactor). In the early phases of a severe accident, the fuel temperature increased due to the decay heat. When the temperature reached approximately $1,473 \mathrm{~K}$, the rapid oxidation of $\mathrm{Zr}$ began, leading to the collapse of fuel ${ }^{2)}$. In a thermodynamic evaluation, this phenomenon is shown as a variation in the molar ratio between $\mathrm{Zr}$ and $\mathrm{ZrO}_{2}$, when the molar quantity of steam that effectively reacts with $\mathrm{Zr}$ is indicated on the horizontal axis (as given in the left half of the figure). In this zone, $\mathrm{g}\left(\mathrm{O}_{2}\right)$ is maintained at a constant value for each temperature because the oxidation of $\mathrm{Zr}$ specifies the $\mathrm{g}\left(\mathrm{O}_{2}\right)$ of the system. The value of $\mathrm{g}\left(\mathrm{O}_{2}\right)$ increases with temperature. In this study, case-I (added $\mathrm{H}_{2} \mathrm{O}$ amount: 1.5 mole) was selected as a typical condition in the early phases of a severe accident. This is equivalent to the chemical condition in which approximately $50 \%$ of $\mathrm{Zr}$ is oxidized. Here, the gram atomic weight of the chemical compound is treated as the sum of the atom weight that compose it. For example, 1 mole of $\mathrm{ZrO}_{2}$ is plotted as 3 moles, the sum of 1 atom of $\mathrm{Zr}$ and 2 atoms of $\mathrm{O}$, in the figure. In an actual severe accident, a higher value of $\mathrm{g}\left(\mathrm{O}_{2}\right)$ on the periphery of claddings is expected due to the interaction with coolant (steam), but this effect is not considered in the present analysis. Furthermore, in real fuel rods, the change in $\mathrm{O} / \mathrm{M}$ of $\mathrm{UO}_{2}$ with respect to the oxygen partial pressure is not negligible when evaluating the chemical properties of degraded fuel. However, in this study, the latter was not considered for conducting a thermodynamic evaluation of the chemical status of FP or the seawater 


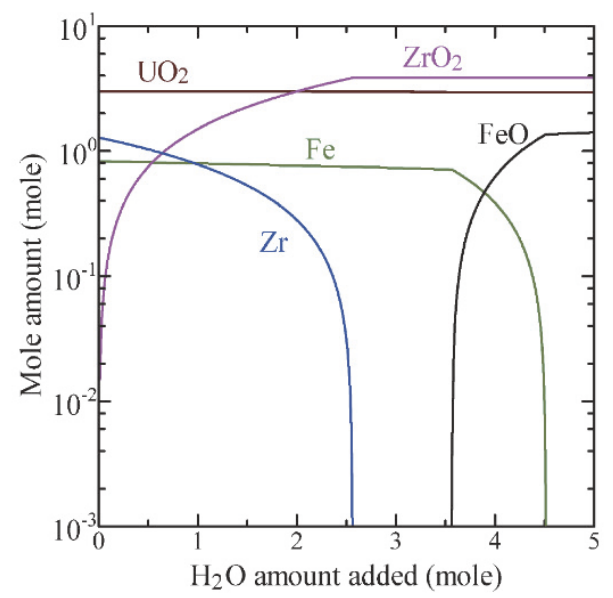

Figure 2 Variation in mole-amount of $\mathrm{U}, \mathrm{Zr}$, and Fe species with respect to added water amount (at 2,500 K)

components because the Gibbs free energy for the dissolution of the elements in $\mathrm{UO}_{2}$ is far smaller than that for the formation of compounds between FP and the seawater components. The change in $\mathrm{O} / \mathrm{M}$ scarcely influences these changes in chemical conditions, as $\mathrm{UO}_{2}$ was treated with a fixed $\mathrm{O} / \mathrm{M}=2.0$.

In the late phases of a severe accident, $\mathrm{g}\left(\mathrm{O}_{2}\right)$ rapidly increases due to the oxidation of almost all the $\mathrm{Zr}$ and is regulated by the partial pressure of $\mathrm{H}_{2} / \mathrm{H}_{2} \mathrm{O}$ (as shown in the right half of Figure 1). In this zone, the oxidation of $\mathrm{Fe}$ that was originally part of the structure begins when $\mathrm{g}\left(\mathrm{O}_{2}\right)$ exceeds a certain value. The relation of the added amount of $\mathrm{H}_{2} \mathrm{O}(0.827$ mole of $\mathrm{Fe}, 1$ mole of $\mathrm{UO}_{2}$, and 1.282 mole of $\mathrm{Zr}$ ), and the oxidation status of $\mathrm{U}, \mathrm{Zr}$, and $\mathrm{Fe}$ is shown in Figure 2 (at a temperature of 2,500 K). In an oxidative atmosphere, the oxidation of Fe occurs by the addition of a certain amount of $\mathrm{H}_{2} \mathrm{O}$. Based on these observations, case-II (added $\mathrm{H}_{2} \mathrm{O}$ amount: 3.7 mole) was selected as a typical condition for the partial oxidation of structural materials in the late phases of a severe accident. In an actual severe accident, a portion of the structural materials might be locally oxidized in the early phases as well, but that is not considered here. Furthermore, when an absorber material such as $\mathrm{B}_{4} \mathrm{C}$ contributes to the chemical reactions, the change in oxygen potential will further differ, but the analysis was conducted elsewhere ${ }^{9)}$.

In the present analyses, assuming that the fuel containing FP and zircalloy reacted with pure water, as in case-I and case-II, respectively, the variation in composition of the stable solid phases and those in the gaseous phase as functions of temperature and oxygen potential were evaluated in the first step, and the reaction with seawater was discussed in the second step. Then, the difference in the trend was discussed. Furthermore, the contribution of the structural materials was discussed as well as the contribution of the oxidative atmosphere.

\section{Results}

\section{Chemical Reaction of $\mathrm{UO}_{2} / \mathrm{FP} / \mathrm{Zr}$ Mixture and Pure Water}

Figure 3 shows the relationship between the added water amount and the gram atomweight quantity of solid phases, and the relation between the added water amount and the mole fraction of gaseous phases, evaluated at 1,500 K and 2,500 K, respectively. A significant variation in the chemical species between oxidative and reductive atmospheres is seen in both the gaseous 

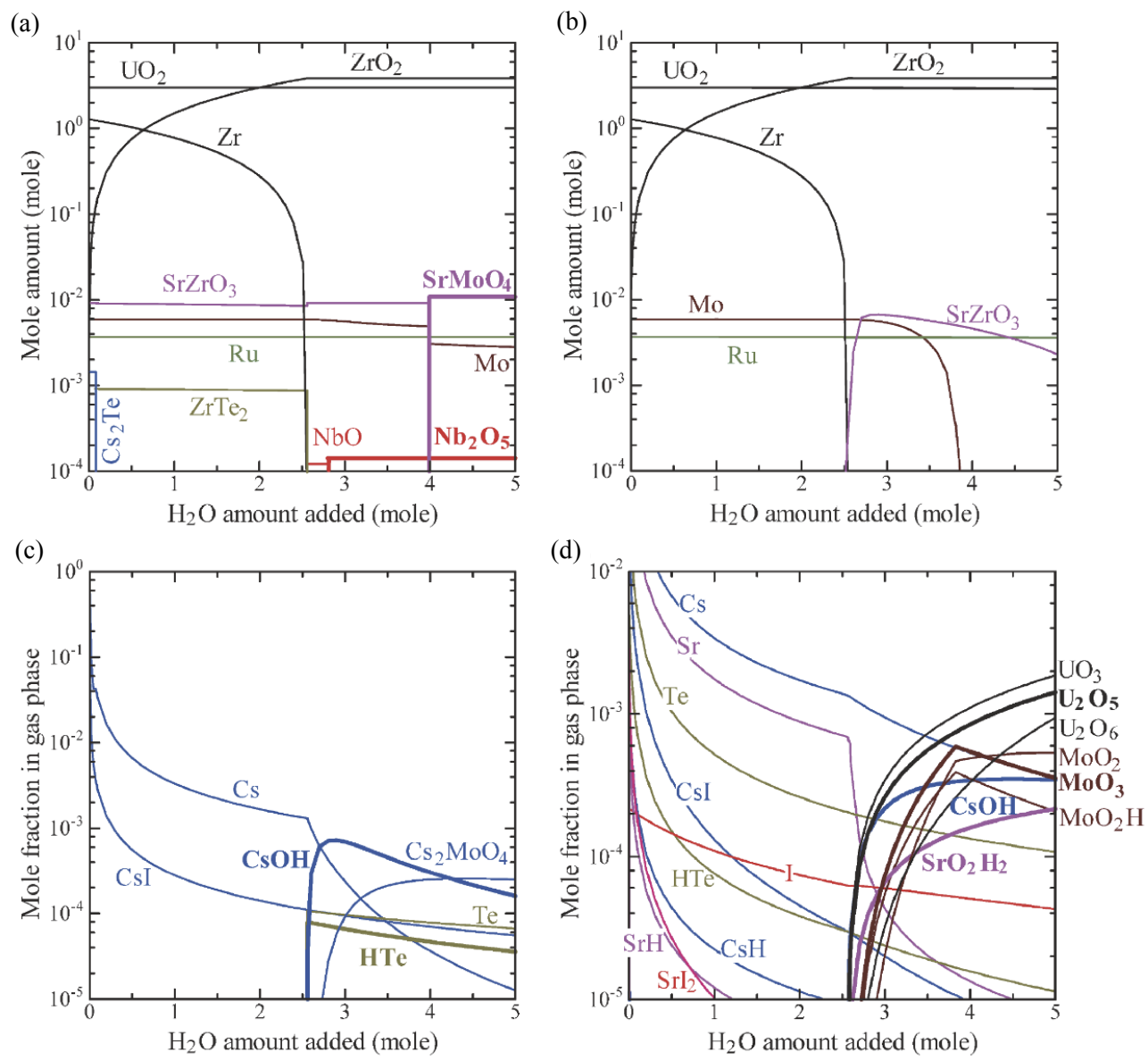

Figure 3 Variation in fission product species with respect to water amount added

(a) Mole amount of solid species (1,500 K), (b) Mole amount of solid species (2,500 K), (c) Mole fraction of gas species $(1,500 \mathrm{~K})$, and (d) Mole-fraction of gas species $(2,500 \mathrm{~K})$

and solid phases. In the solid phase, $\mathrm{ZrTe}_{2}$ and $\mathrm{Cs}_{2} \mathrm{Te}$ are stable in a reductive atmosphere at $1,500 \mathrm{~K}$. In an oxidative atmosphere, $\mathrm{Nb}$ oxides are stable. $\mathrm{SrZrO}_{3}$ is stable as well and is evaluated as transforming to $\mathrm{SrMoO}_{4}$ as $\mathrm{g}\left(\mathrm{O}_{2}\right)$ increases. Mo is generally stable as metallic Mo, but when a certain $\mathrm{g}\left(\mathrm{O}_{2}\right)$ is exceeded, it will form complex oxides with Sr. The metal solid phase of $\mathrm{Ru}$ is stable in this $\mathrm{g}\left(\mathrm{O}_{2}\right)$ range, and volatile high-order oxides are rarely formed. When the temperature rises to $2,500 \mathrm{~K}$, no $\mathrm{Sr}$ oxides are formed in a reductive atmosphere.

Furthermore, metallic Mo disappears in an oxidative atmosphere. This is attributable to the evaporation of $\mathrm{Sr}$ in a reductive atmosphere and Mo oxides in an oxidative atmosphere.

Regarding the gaseous phase, the elements that show significant evaporation in a reductive atmosphere at $1,500 \mathrm{~K}$ are $\mathrm{Cs}$ and $\mathrm{I}$, and it is shown that all the I evaporates as CsI and a part of Cs evaporates as single atoms of Cs. In an oxidative atmosphere, the evaporation of Mo and Te is observed in addition to $\mathrm{Cs}$ and $\mathrm{I}$, and it is shown that $\mathrm{CsOH}$ and $\mathrm{Cs}_{2} \mathrm{MoO}_{4}$ are added to the evaporating chemical forms of Cs. Te evaporates as single Te and in HTe. Because there are many evaporating species at 2,500 K, the scale factor of the y-axis is changed (Figure 3 (d)). In a reductive atmosphere, $\mathrm{Sr}$ and $\mathrm{Te}$ evaporate in addition to $\mathrm{Cs}$ and $\mathrm{I}$. As for $\mathrm{Sr}$, evaporation of single $\mathrm{Sr}$ is dominant. Te evaporates as single Te or as HTe. At this temperature, it is evaluated 
(a)

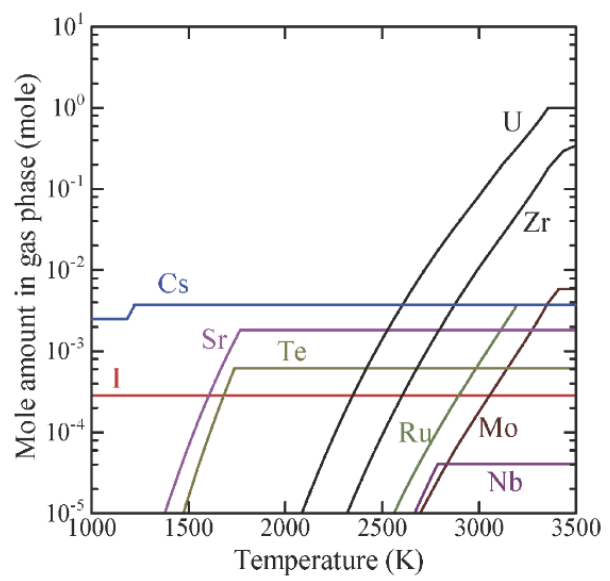

(b)

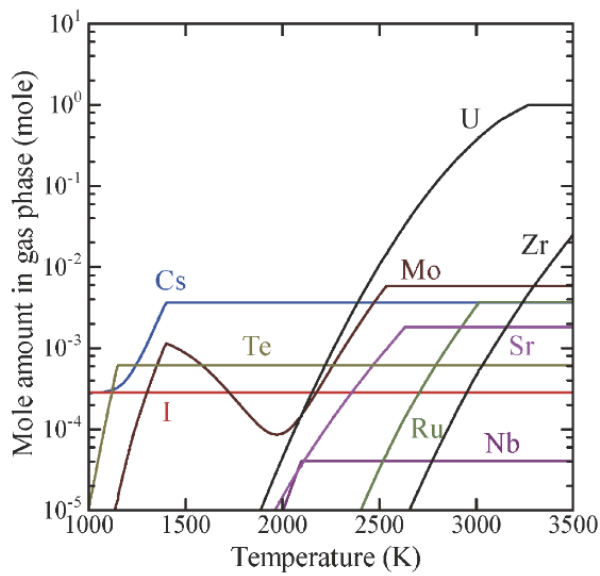

Figure 4 Mole amount in gas phase as a function of temperature

(a) reductive atmosphere (case-I) and (b) oxidative atmosphere (case-II)

that a portion of the gaseous phase of CsI decomposes, and single I and $\mathrm{SrI}_{2}$ evaporate as well. Meanwhile, in an oxidative atmosphere, high-order oxides of elements such as U and Mo evaporate. The percentage of single $\mathrm{Cs}$ decreases, and $\mathrm{CsOH}$ becomes the major component of $\mathrm{Cs}$, and as high-order oxides of Mo become stable, the complex oxides of the Cs-Mo system are not formed. $\mathrm{Sr}(\mathrm{OH})_{2}$ becomes the major form of $\mathrm{Sr}$.

The evaluation results of the molar quantity of gaseous phases for various elements in case-I and case-II are shown in Figure 4. By observation, including Figure 3, the general trend of evaporation is understood for both reductive and oxidative atmospheres for various elements:

$\mathrm{U}$ : Slightly evaporates in an oxidative atmosphere because of the formation of vapor species of high-order oxides.

$\mathrm{Zr}$ : Slightly evaporates in an oxidative atmosphere because of the slightly higher vapor pressure of metals compared with that of oxides.

$\mathrm{Sr}$ : Readily evaporates in a reductive atmosphere because of the easily decomposing nature of $\mathrm{SrZrO}_{3}$ in a reductive atmosphere.

$\mathrm{Nb}$ : Readily evaporates in an oxidative atmosphere because of the formation of vapor species of high-order oxides.

Mo: Readily evaporates in an oxidative atmosphere because of the formation of vaporous high-order oxides.

$\mathrm{Ru}$ : Slightly evaporates in an oxidative atmosphere because of the slightly higher vapor pressure of oxides compared with that of metals.

Te : Readily evaporates in an oxidative atmosphere because of the formation of the comparatively stable solid phase $\mathrm{ZrTe}_{2}$ on the reductive side.

I : Readily evaporates under this condition.

Cs : Readily evaporates but slightly inhibited because of the formation of a $\mathrm{Cs}_{2} \mathrm{MoO}_{4}$ type compound in a lower temperature zone of an oxidative atmosphere.

\section{Chemical Reaction of $\mathrm{UO}_{2} / \mathrm{FP} / \mathrm{Zr}$ Mix and Seawater}

It is highly unlikely that seawater reacts directly with the damaged fuel as it contains the original concentrations. Hence, a condition is assumed in which the $\mathrm{H}_{2} \mathrm{O}$ molar quantity is 1.0 , 
and an analysis was conducted by varying the $\mathrm{H}_{2} \mathrm{O}$ quantity by a factor of 5 , so the $\mathrm{H}_{2} \mathrm{O}$ molar quantity is 5.0. Figure 5 shows the relation between added seawater amount and the molar quantity of solid formed at 1,500 K and 2,500 K. By comparison with Figure 3, the expected influence of the reaction with seawater, when it occurs, is evaluated.

(Temperature: $1,500 \mathrm{~K}$ )

$\mathrm{Sr}$ : The chlorides and sulfates are formed in a reductive atmosphere. No change occurs in an oxidative atmosphere.

$\mathrm{Nb}$ : The oxide species are changed to higher-order species in an oxidative atmosphere.

Mo : Complex oxides of $\mathrm{Na}$ and $\mathrm{Ca}$ are formed in an oxidative atmosphere. No change occurs in a reductive atmosphere.

$\mathrm{Ru}$ : No change.

Te : CaTe is formed in a reductive atmosphere.

I : Solid phase is not formed.

$\mathrm{Cs}: \mathrm{Cs}_{2} \mathrm{Te}$ is decomposed in a reductive atmosphere.

(Temperature: $2,500 \mathrm{~K}$ )

$\mathrm{Sr}$ : Decomposition of $\mathrm{SrZrO}_{3}$ is slightly accelerated in an oxidative atmosphere.
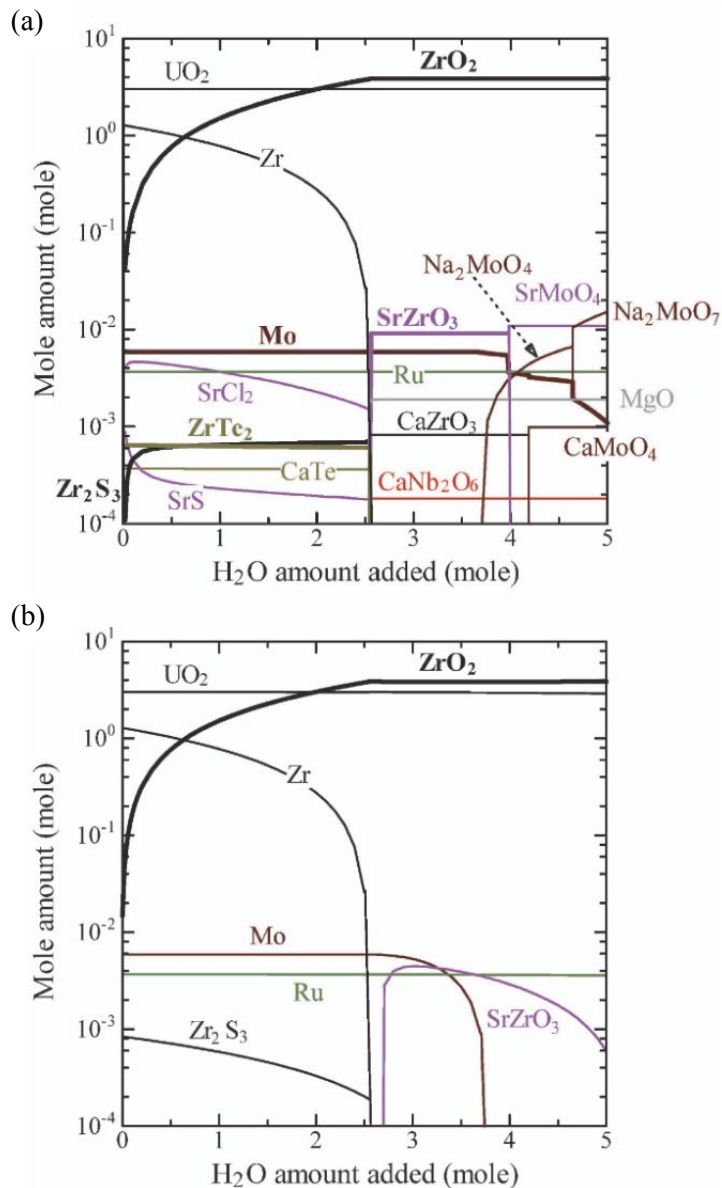

Figure 5 Mole amount of solid species as a function of water amount added in the case of seawater (a) $1,500 \mathrm{~K}$ and (b) $2,500 \mathrm{~K}$ 
Mo : Evaporation of Mo is slightly accelerated in an oxidative atmosphere.

$\mathrm{Ru}$ : No change.

Other FPs: Solid phase does not exist.

In a similar manner, the relation between added seawater amount and the molar fraction of the gaseous phase is shown in Figure 6. Here, the components originating mainly from FP and other components are separately shown for $2,500 \mathrm{~K}$ due to space limitations.

(Temperature: $1,500 \mathrm{~K}$ )

$\mathrm{Sr}$ : Chloride vapor species are formed in a reductive atmosphere, and evaporation is accelerated.

Mo: Vapor species of composite oxides with Cs are not formed in a reductive atmosphere, and evaporation is suppressed.

I : Formation of $\mathrm{NaI}$ becomes dominant in an oxidative atmosphere. Even in a reductive atmosphere, $\mathrm{NaI}$ exists in addition to CsI.

$\mathrm{Cs}: \mathrm{CsCl}$ is the major component of vapor species in both reductive and oxidative atmospheres, and evaporation is accelerated. The vapor species of complex compounds with Mo are not formed in an oxidative atmosphere.

Others: Significant generation of $\mathrm{HCl}$ in an oxidative atmosphere.

(Temperature: $2,500 \mathrm{~K}$ )

$\mathrm{U}$ : Evaporation is slightly accelerated in a reductive atmosphere because of the formation of vapor species of chlorides.

$\mathrm{Sr}$ : Chloride vapor species are formed in a reductive atmosphere, and evaporation is accelerated. Vapor species are transformed in an oxidative atmosphere.

Mo: Vapor species are transformed in an oxidative atmosphere.

I : $\mathrm{NaI}$ is formed in a reductive atmosphere.

$\mathrm{Cs}: \mathrm{CsCl}$ and $\mathrm{Cs}$ become the major components of vapor species both in reductive and oxidative atmospheres.

The temperature dependence of the evaporation rate for various elements in a reductive atmosphere (case-I) and an oxidative atmosphere (case-II) is shown in Figure 7. Trends for each element are evaluated by comparison with Figure 4.

(Reductive atmosphere: case-I)

$\mathrm{U}, \mathrm{Zr}, \mathrm{Nb}, \mathrm{Mo}, \mathrm{Ru}, \mathrm{Te}$, and I: No significant influence

$\mathrm{Sr}$ and $\mathrm{Cs}$ : Acceleration of evaporation

(Oxidative atmosphere: case-II)

$\mathrm{U}, \mathrm{Zr}, \mathrm{Ru}, \mathrm{Te}$, and I: No significant influence

$\mathrm{Sr}$ and $\mathrm{Cs}$ : Acceleration of evaporation

$\mathrm{Mo}$ and $\mathrm{Nb}$ : Inhibition of evaporation

\section{Generation of Corrosive Gas from Seawater}

Figure 8 extracts the evaluation results on corrosive gas components from the temperature dependence in the molar quantity of vapor species for case-I and case-II. The trends for each element are shown in Figure 7, and the trends are indicated for each vapor species in Figure 8. It is confirmed that the dominant vapor species for evaporation of each element changes depending on the temperature, and the trends vary significantly between reductive and oxidative atmospheres. The generation of the major corrosive gases is shown in the same figure. In a reductive atmosphere, corrosive gases such as $\mathrm{HCl}, \mathrm{HS}, \mathrm{H}_{2} \mathrm{~S}$, and $\mathrm{S}$, are generated. In an oxidative atmosphere, $\mathrm{SO}$ and $\mathrm{SO}_{2}$ are generated in addition to the gases observed in a reductive atmosphere. These corrosive gases likely start to form in the comparatively low temperature 

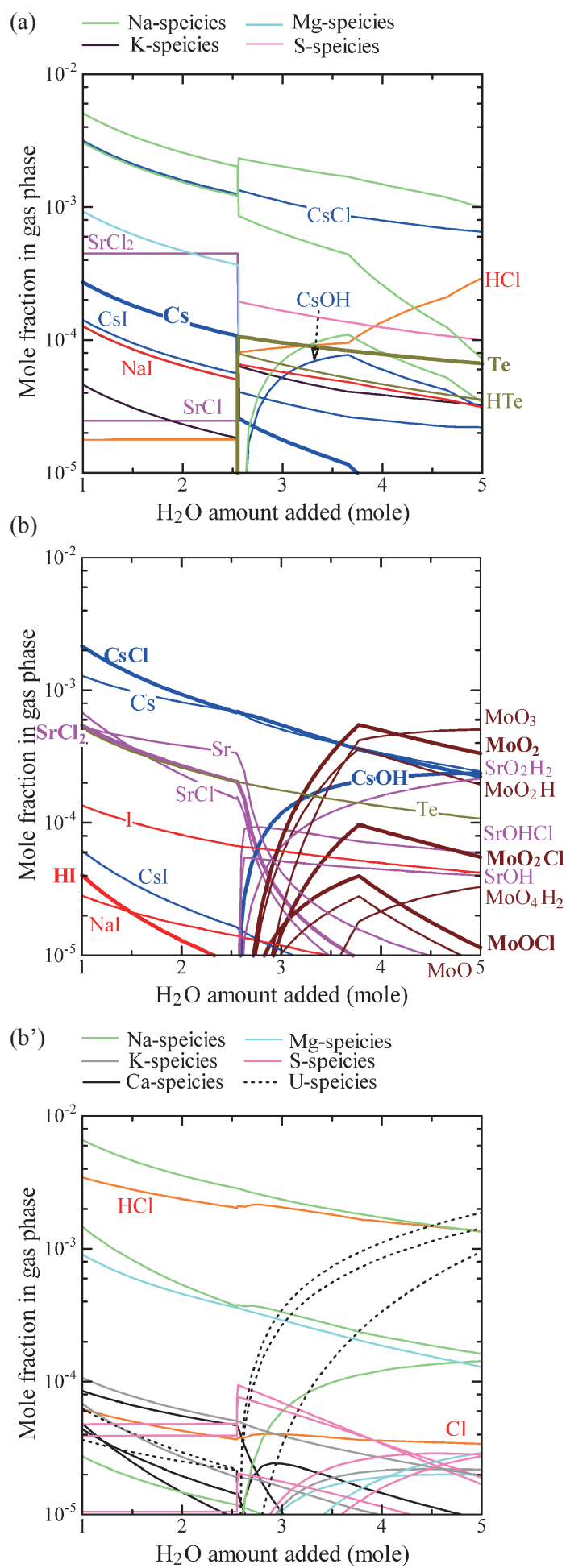

Figure 6 Mole fraction of gas species as a function of water amount added in the case of seawater (a) 1,500 K, (b) 2,500 K(FP), and (b') 2,500 K(others) 
(a)

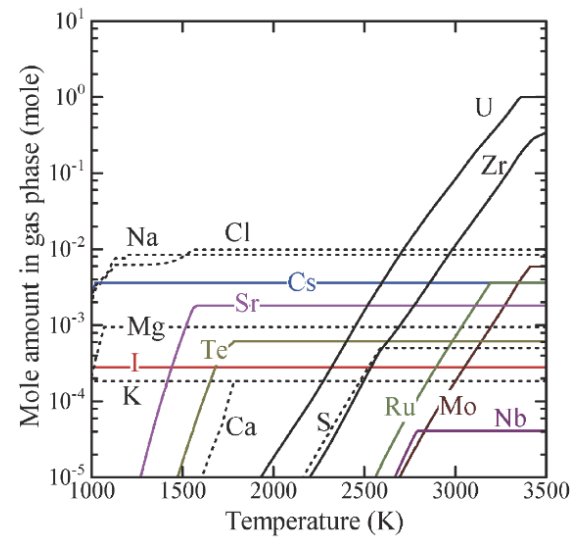

(b)

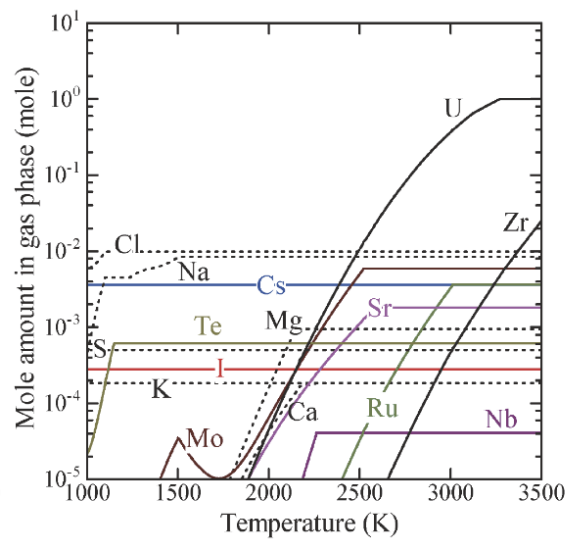

Figure 7 Mole amount in gas phase as a function of temperature in the case of seawater (a) reductive atmosphere (case-I) and (b) oxidative atmosphere (case-II)

(a)

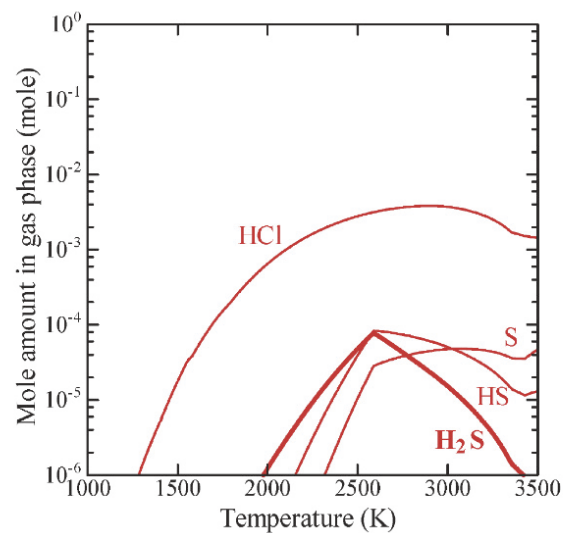

(b)

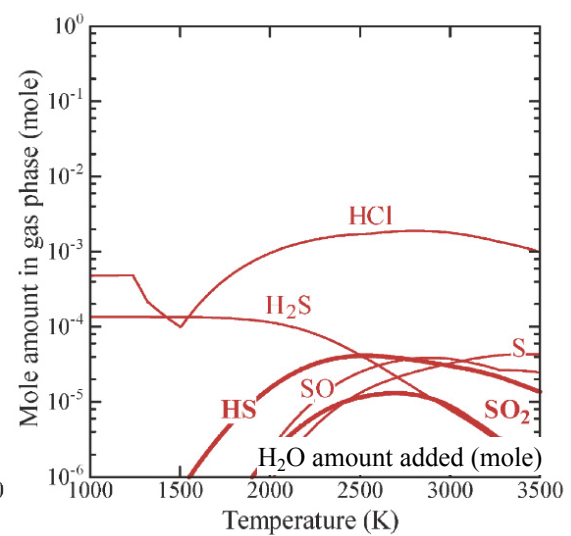

Figure 8 Mole amount in gas phase as a function of temperature in the case of seawater (a) reductive atmosphere (case-I) and (b) oxidative atmosphere (case-II)

regions in an oxidative atmosphere. This implies the possibility of a significant change in the trend of corrosive gas generation, depending on the time when seawater is supplied to the damaged reactor core. The later the seawater is supplied after the increase in $g\left(\mathrm{O}_{2}\right)$ in the system in the late stages of an accident, the more corrosive gases are likely to be generated.

\section{Chemical Reaction of $\mathrm{UO}_{2} / \mathrm{FP} / \mathrm{Zr} / \mathrm{Fe}$ Mix and Seawater}

For similar conditions as above, an evaluation was performed for the Fe from structural materials. Figure 9 shows the temperature dependence of the evaporated molar quantity for each element in case-I and case-II. Because $\mathrm{g}\left(\mathrm{O}_{2}\right)$ changes in an oxidative atmosphere through the coexistence of $\mathrm{Fe}$ oxide, a slight difference in the evaporation properties of Mo and $\mathrm{Te}$ is observed. It is shown that for both elements, an acceleration of evaporation takes place at low temperatures. A slight acceleration in the evaporation of seawater components such as $\mathrm{Na}$ and $\mathrm{Cl}$ likely takes place at low temperatures in an oxidative atmosphere. 
(a)

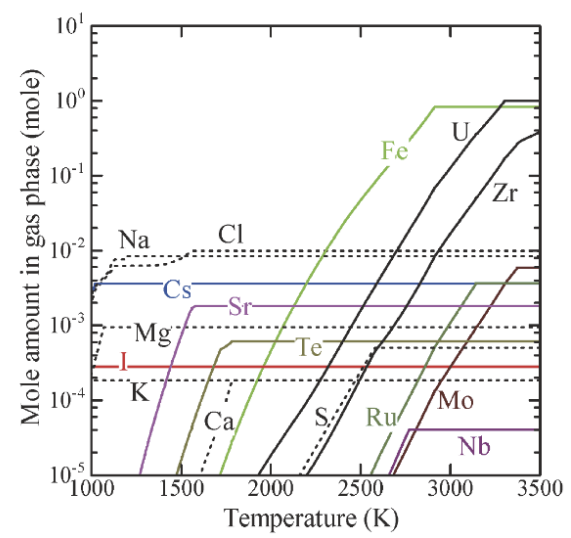

(b)

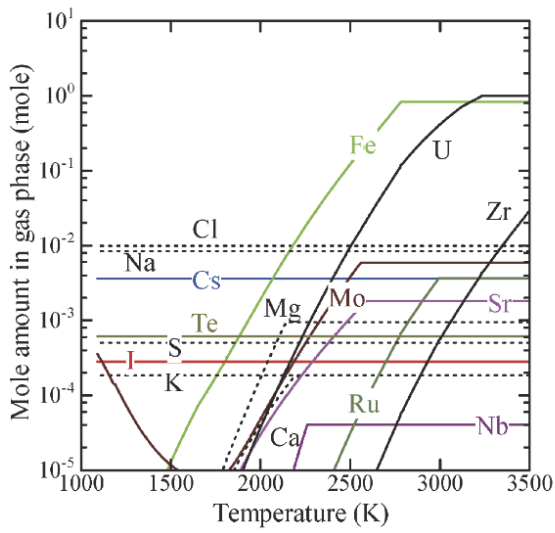

Figure 9 Mole amount in gas phase as a function of temperature in the case of the coexistence of seawater and steel (a) reductive atmosphere (case-I) and (b) oxidative atmosphere (case-II)

However, the possibility of complicated chemical reactions due to the coexistence of seawater and $\mathrm{Fe}$ is considered to be low. The details of the reaction of damaged fuel and structural materials is explained elsewhere ${ }^{4)}$.

\section{Discussion}

Based on the present evaluation results, concerns requiring further discussion are presented regarding the degradation of fuel.

\section{Heterogeneity of Damaged Reactor Vessel Interior}

As shown in Figure 5, when the reaction between damaged fuel and seawater takes place in a reductive atmosphere, $\mathrm{Zr}_{2} \mathrm{~S}_{3}$ may be formed. On the other hand, as shown in Figure 8, $\mathrm{SO}_{\mathrm{x}}$ gas is generated if seawater is heated in an oxidative atmosphere. The temperature and $g\left(\mathrm{O}_{2}\right)$ differ markedly at each location in a damaged reactor vessel in an actual severe accident and is further expected to vary minute by minute. Consequently, fuels are considered to collapse in a heterogeneous manner. Concerns caused by such heterogeneity are revealed by the current thermodynamic approach. In an example of sulfide formation, $\mathrm{g}\left(\mathrm{O}_{2}\right)$ increases in the molten corium when the damage of fuel progresses. The $\mathrm{SO}_{\mathrm{x}}$ gas, which is considered to be generated when the molten corium and seawater react, is transferred to the comparatively low temperature regions, where zircalloy metal remains, because the damage is not as thorough and extensive, and may sulfurize zircalloy and accelerate the damage. It is necessary to continue the analyses of these heterogeneous processes in future study.

\section{Extension of Database}

As explained in section II, the organization of a thermodynamic database is essential to the improved accuracy of thermodynamic evaluation. Because almost no data regarding oxy-chlorides of $\mathrm{U}$ and $\mathrm{Zr}$ (e.g., $\mathrm{UOCl}, \mathrm{ZrOCl}$ ) are available in the SSUB4 database, the influence of 
the evaporation of $\mathrm{U}$ and $\mathrm{Zr}$ in the case of reaction with seawater was not predicted. However, oxy-chlorides may accelerate the evaporation of $U$ and $\mathrm{Zr}$ because they have higher vapor pressures than the oxides of those elements. This implies the possibility of the adhesion of $U$ in an unanticipated location in the reactor core during an accident. Furthermore, it is necessary to consider the effect of various compounds present as solid or liquid solutions as related to the evaporation behavior or formation of chemical compounds. Because there are no thermodynamic data on $\mathrm{CsBO}_{2}$, relevant evaluation was not possible in this study. It is essential to systematically upgrade that data by referring to current evaluation results and various experimental data currently being collected. Here, a certain prioritization is necessary for extracting important data. For this purpose, sensitivity analysis assuming hypothetical data is likely to be considered. Research and development should be conducted both experimentally and analytically.

\section{Evaluation of Hydrogen Concentration and Prediction of Oxygen Potential $\left(\mathrm{g}\left(\mathbf{O}_{2}\right)\right)$}

In the late phases of a severe accident, the hydrogen partial pressure in steam is considered to be extremely low because the oxidation of zirconium almost ceases. In the current evaluation, all the analyses were conducted based on the assumption of a closed system. Therefore, they were always treated under the condition of a coexistence of a certain amount of hydrogen. To simulate the late phases of a severe accident with better accuracy, it is necessary to switch to an evaluation condition in which no residual hydrogen is assumed in the system at any stage of the accident. This analysis will be conducted along with simulation tests in the future. The properties of debris sampled from the reactors will also be referred to. A reverse estimation of $\mathrm{g}\left(\mathrm{O}_{2}\right)$ and temperature during real accident progression might be performed based on this knowledge of chemical behavior. This will contribute to the presumption of evaporation for the main FPs. It can be pointed out that the location of Mo and $\mathrm{Nb}$, potentially detected in the future in the damaged reactors, might be a very useful hint in evaluating accident progression.

\section{Summary}

A thermodynamic evaluation was conducted on the predicted chemical reactions when seawater is injected and contacts the degraded fuel under severe accident conditions, yielding the following results:

(1) Influence on volatile FPs: In an environment where a large amount of $\mathrm{Zr}$ remains in the early phases of a severe accident, due to the reaction between $\mathrm{FP}$ and $\mathrm{Na}, \mathrm{Cl}$, or other sub-components, such as $\mathrm{K}, \mathrm{Ca}, \mathrm{Mg}$, and $\mathrm{S}$ in seawater, the evaporation of $\mathrm{Sr}$ and $\mathrm{Cs}$ is likely to be accelerated compared to the situation in pure water or steam. Furthermore, in an environment with progressing oxidation of $\mathrm{Zr}$ in the late phases of a severe accident, the evaporation of $\mathrm{Sr}$ and $\mathrm{Cs}$ is likely to be accelerated, while that of $\mathrm{Mo}$ and $\mathrm{Nb}$ is suppressed.

(2) Generation of corrosive gases: Where the seawater is exposed to the high temperature environment in the reactor under the conditions of the early phases of a severe accident, corrosive gases, such as $\mathrm{HCl}, \mathrm{HS}, \mathrm{H}_{2} \mathrm{~S}$, and $\mathrm{S}$, are likely to be generated. In the late phases of a severe accident, those gases are even more likely to be generated, and $\mathrm{SO}$ and $\mathrm{SO}_{2}$ might be generated as well.

(3) Influence of structural materials: The presence of structural materials is likely to influence the variation in the oxygen potential in the reactor under severe accident conditions, but 
collateral chemical reactions due to the coexistence of the structural materials and seawater is unlikely to be common.

(4) Others: One of the key questions in the evaluation of the degraded core status is, "in which location in the degraded reactor core are $\mathrm{Mo}$ and $\mathrm{Nb}$, whose evaporation properties are presumably greatly influenced by chemical conditions (e.g., oxygen potential), detected?"

In the next step of our study, the analyses of heterogeneous open systems will be continued in parallel with the progress in various other experiments.

The authors are grateful to Drs. Kazuo Minato, Yasuo Arai, Fumihisa Nagase and Masahide Takano of the Japan Atomic Energy Agency for their valuable comments. The authors are also grateful to Dr. Kenji Nishihara of the same agency, who kindly provided the evaluation values of FP using the ORIGEN-II code.

\section{References}

1) M. Takano, T. Nishi, M. Kurata et al., "High temperature reaction between $\mathrm{UO}_{2}$ and sea salt deposit," Proc. of 5th European Review Meeting on Severe Accident Research, Mar. 21-23, 2012, Cologne, Germany.

2) P. Hofmann, S. Hagen, G. Schanz, A. Skokan, "Reactor core materials interactions at very high temperatures," Nucl. Technol., 87, 146-186 (1989).

3) A. C. Gregoire, T. Haste, "Material release from degraded bundle during the Phebus FP tests," presented at Final seminar of the Phebus FP Programme, Jun. 13-15, 2012, Aix-en-Provence, France, [CD-ROM].

4) Noriko Shirasu, Masaki Kurata, Toru Ogawa "A Thermodynamic Evaluation on the Behavior of $\mathrm{B}_{4} \mathrm{C}$ in an LWR Severe Accident," Journal of Nuclear Science and Technology (in Japanese). (to be published)

5) A. T. Dinsdale, "SGTE data for pure elements," CALPHAD, 15, 317 (1991).

6) B. Sundman, B. Jansson, J.-O. Andersson "The Thermo-Calc databank system," CALPHAD, 9, 153 (1985).

7) L. Cantrel, F. Cousin, L. Bosland, "Advances in mechanistic understanding and modeling of iodine behavior," presented at Final seminar of the Phebus FP Programme, Jun. 13-15, 2012, Aix-en-Provence, France, [CD-ROM].

8) C. Gueneau, N. Dupin, B. Sundman et al., "Thermodynamic modelling of advanced oxide and carbide nuclear fuels: Description of the U-Pu-O-C systems," J. Nucl. Mater., 419, 145 (2011).

9) N. Shirasu, H. Otobe, M. Kurata, "Thermodynamic assessment of the ZrO2-PuO1.5-PuO2 system," $J$. Nucl. Mater., (to be published).

10) F. Tanabe, “Analysis of core melt accident in Fukushima Daiichi-Unit 1 Nuclear Reactor,” J. Nucl. Sci. Technol., 48, 1135 (2011).

11) Y. Nozaki, “A fresh look at element distribution in the North Pacific Ocean,” Eos, 78, 221 (1997).

12) A. G. Croff, A user's Manual for the ORIGEN2 Computer Code, ORNL/TM-7175 (1980). 